Supporting Information

\title{
Modulus of the amorphous phase of semicrystalline polymers
}

Małgorzata Polińska, Artur Rozanski*, Andrzej Galeski, Joanna Bojda

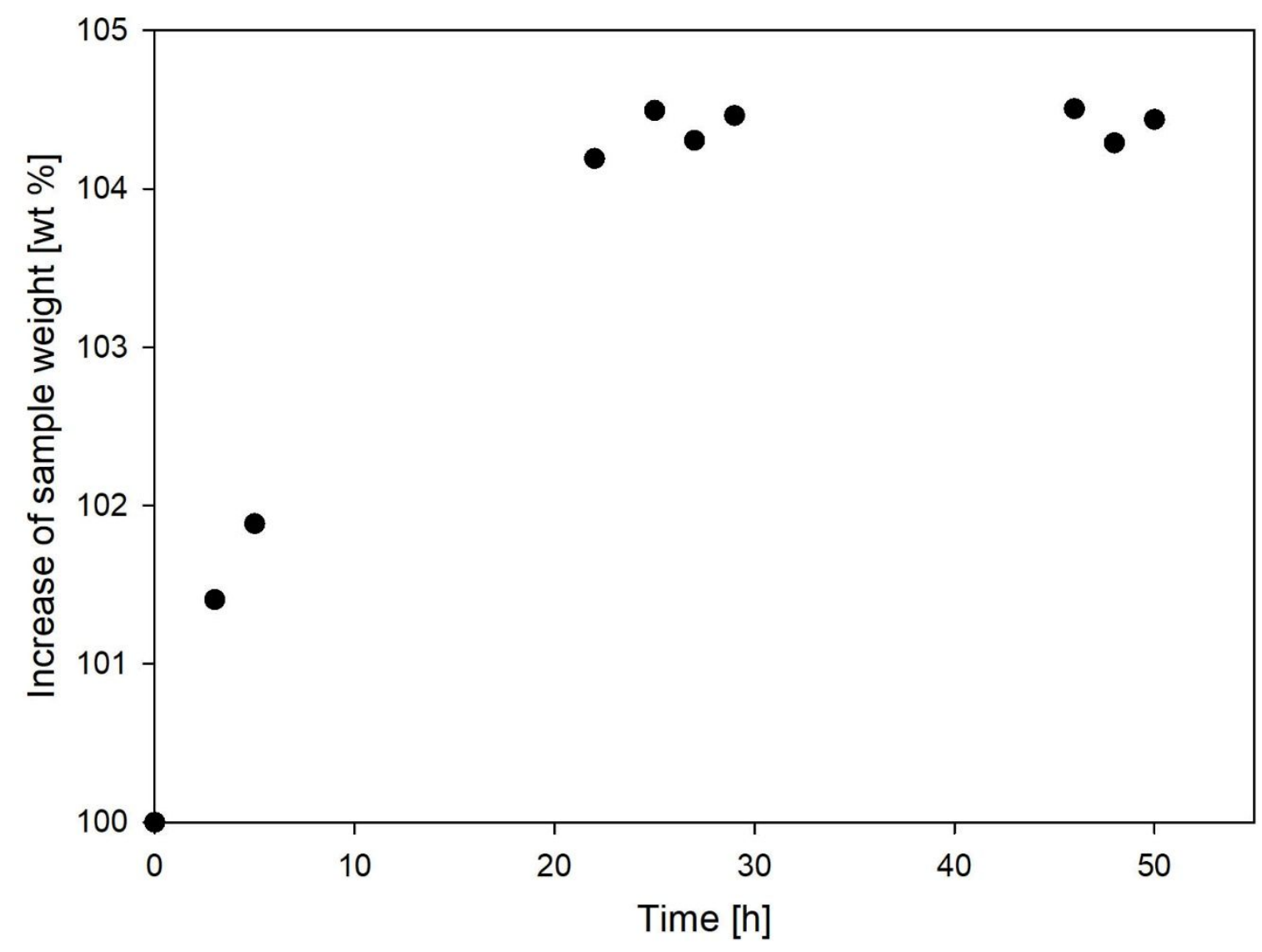

Figure 1S. Kinetics of hexane sorption for high density polyethylene immersed in hexane bath. 


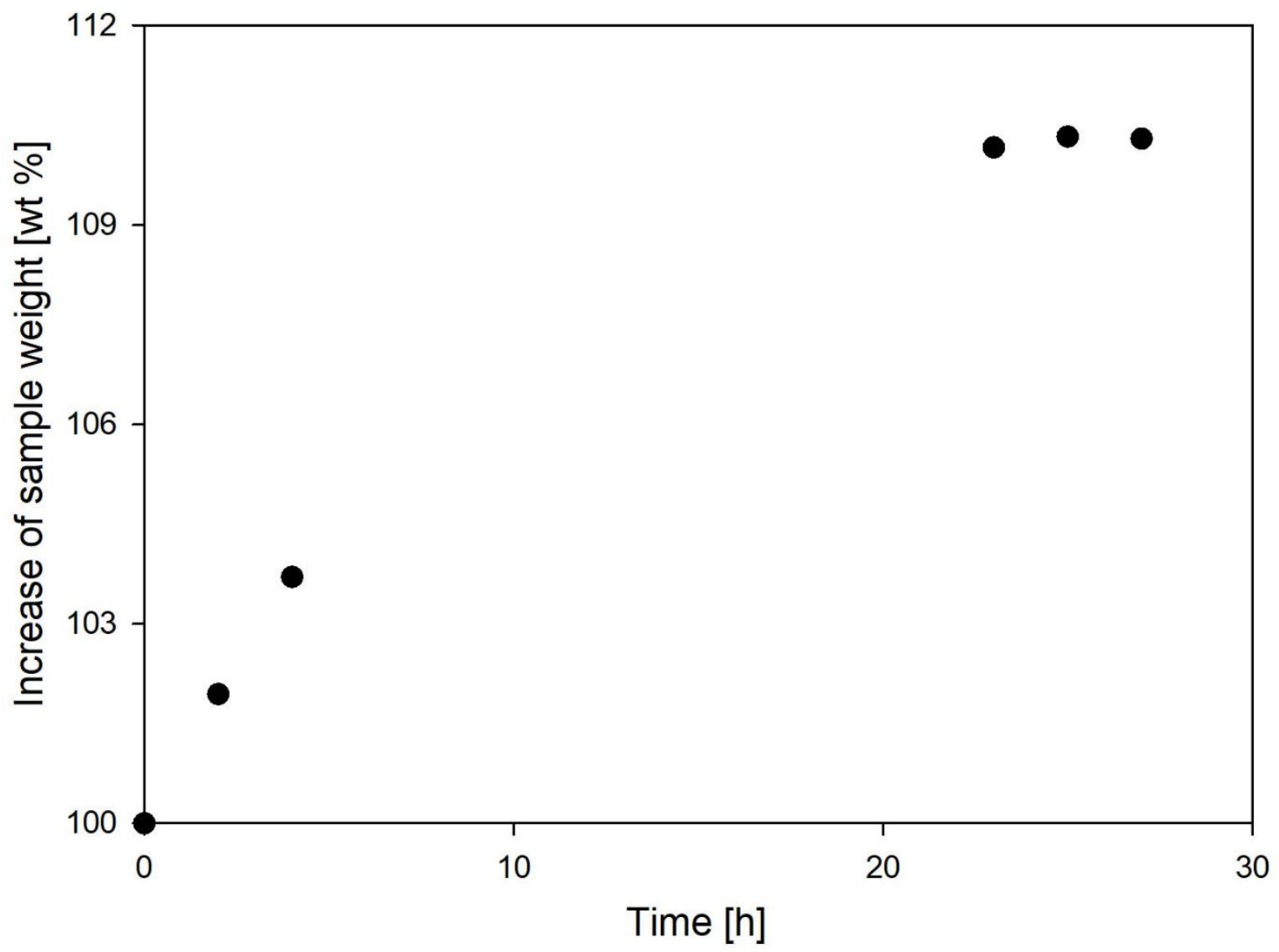

Figure 2S. Kinetics of hexane sorption for polypropylene immersed in hexane bath. 


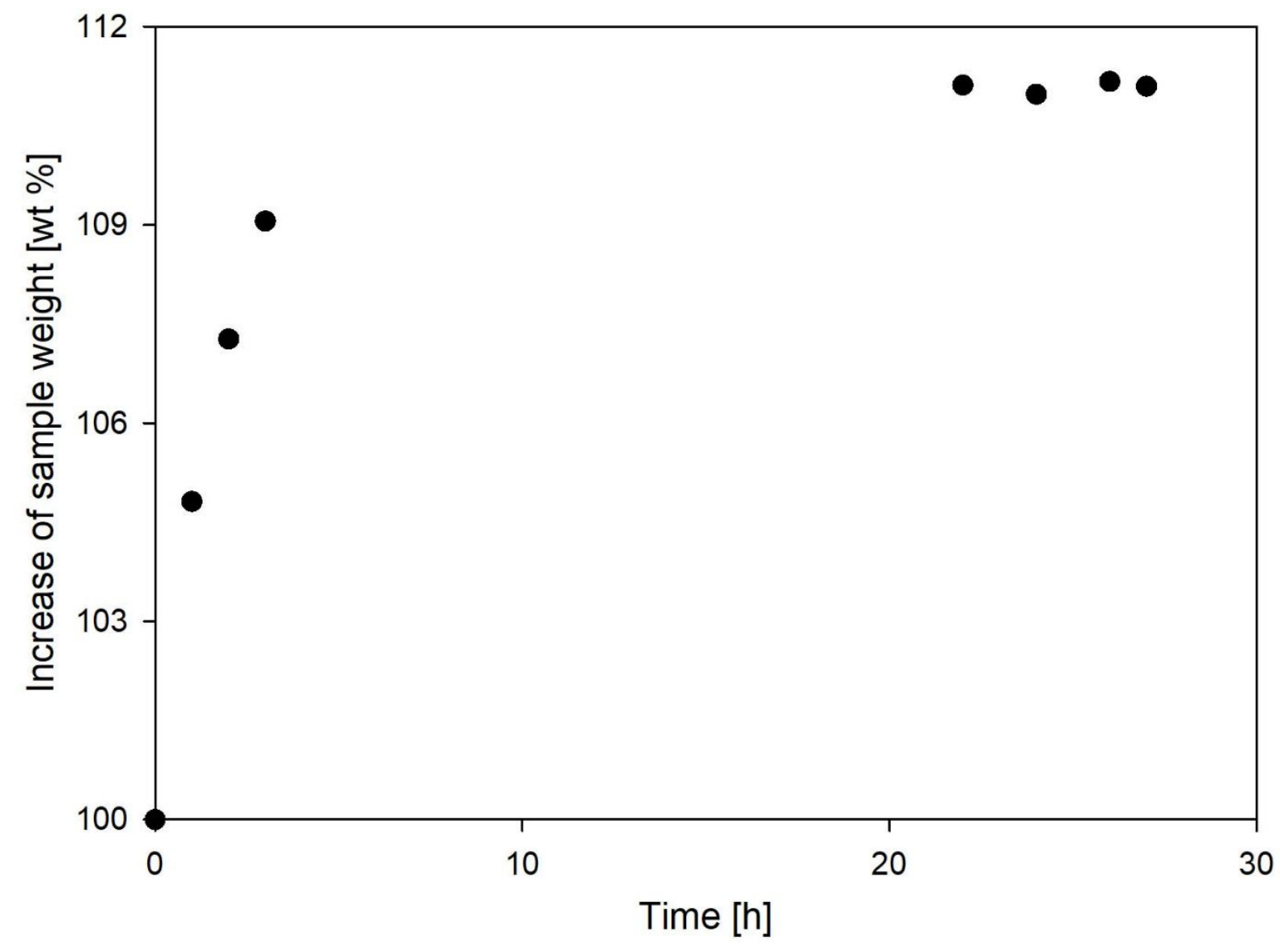

Figure 3S. Kinetics of hexane sorption for low density polyethylene immersed in hexane bath. 


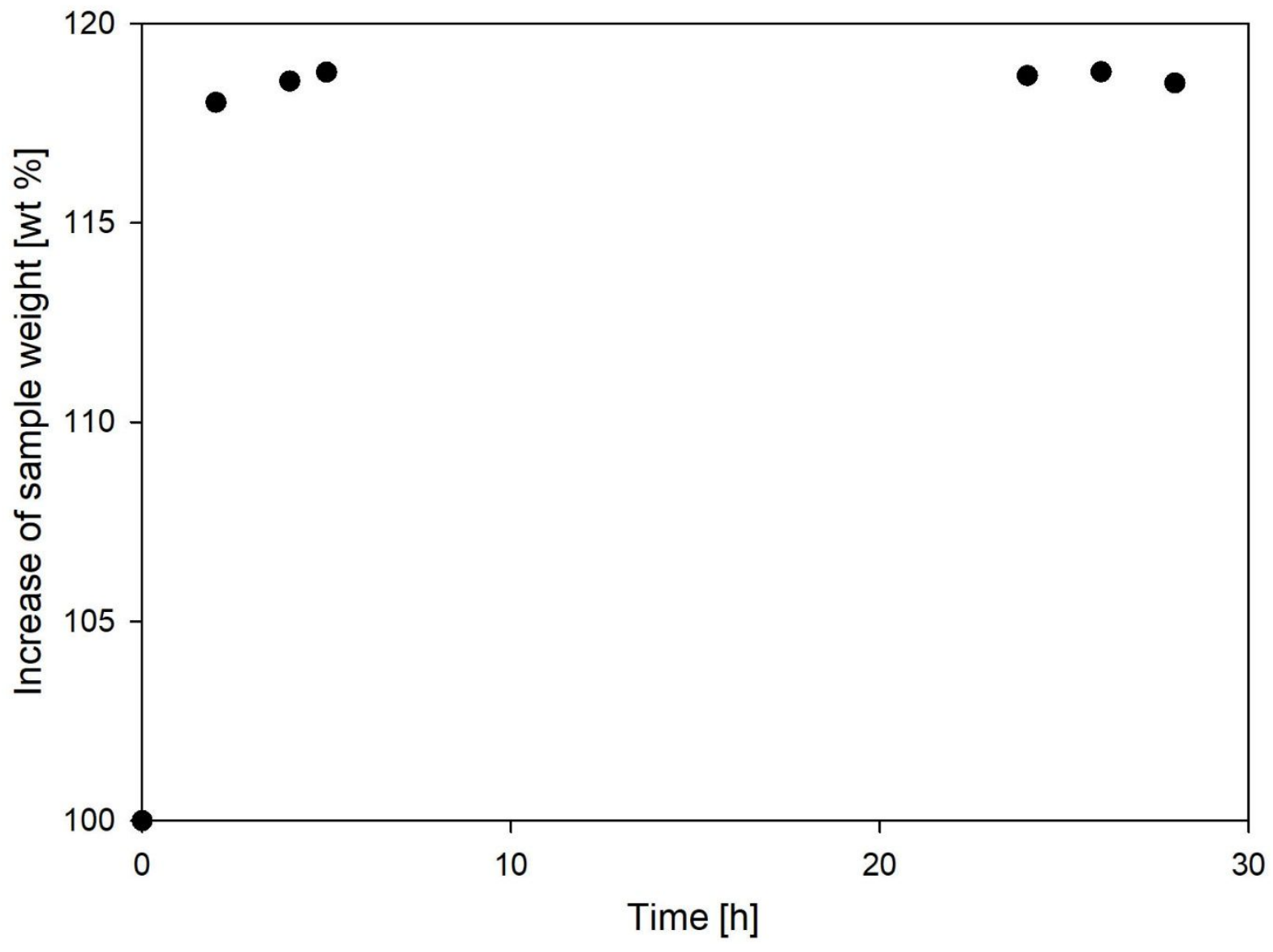

Figure 4S. Kinetics of hexane sorption for ethylene-octane copolymer immersed in hexane bath. 